\title{
LAS KHÁRITES: EN TORNO AL PODER FEMENINO. SABER Y LINAJE
}

\author{
María Cecilia Colombani ${ }^{1}$
}

\section{Resumen}

El objetivo del presente trabajo es determinar la función del discurso mítico en la obra hesiódica como un operador que instituye un universo de sentido que se encuentra entre el mito. Nuestra hipótesis es que en la obra hesiódica se encuentran ciertas imágenes-conceptuales, principalmente las del linaje, que definen el campo de lo Mismo y de lo Otro. En este marco pretendemos analizar la figura de las Khárites asociada a la de las Musas como potencias religiosas para leer formas del poder femenino a partir de un determinado tipo de saber que se despliega en ambos colectivos.

\section{Palabras clave}

Mito, Khárites, Musas, Poder, Saber, Linaje

1 Professora Doctora - Universidad de Morón, Morón, Argentina. E-mail: ceciliacolombani@hotmail.com 


\section{Resumo}

O objetivo do presente trabalho é determinar a função do discurso mítico no trabalho hesiódico como um operador que institui um universo de significados que se encontra entre o mito. Nossa hipótese é que, no trabalho hesiódico, certas imagens conceituais se encontram, principalmente as da linhagem, que definem o campo do Mesmo e do Outro. Nesse contexto, pretendemos analisar a figura das Khárites associada à das Musas como poderes religiosos para ler formas de poder feminino a partir de um certo tipo de conhecimento que se desdobra em ambos os grupos.

\section{Palavras-chave}

Mito, Khárites, Musas, Poder, Conhecer, Linhagem 


\section{Introducción ${ }^{2}$}

El objetivo del presente trabajo es determinar la función del discurso mítico en la obra hesiódica como un operador que instituye un universo de sentido que se encuentra entre el mito. Nuestra hipótesis es que en la obra hesiódica se encuentran ciertas imágenes-conceptuales, principalmente las del linaje, que definen el campo de lo Mismo y de lo Otro. En este marco pretendemos analizar la figura de las Khárites asociada a la de las Musas ${ }^{3}$ como potencias religiosas para leer formas del poder femenino a partir de un determinado tipo de saber que se despliega en ambos colectivos.

Siguiendo a Foucault en el marco de su período arqueológico, entenderemos al mito como una forma de discurso, es decir, como un operador de verdad que determina relaciones de poder-saber. El objetivo es identificar en el discurso hesiódico las estructuras internas de ciertas coordenadas antropológicas: lo divino y lo humano, lo nocturno y lo luminoso, lo humano y lo animal, lo masculino y lo femenino. Se trata de reconstruir las estructuras discursivas que definen esto para entender que es parte de una determinada configuración de época, un magma de significaciones que se está erigiendo, brotando, irrumpiendo, desde las propias ruinas de la configuración mítica; se trata de acompañar el discurso hesiódico para ver cómo despega un nuevo eîdos, una nueva idea de hombre, de mundo, de naturaleza.

El discurso abre el campo de emergencia de una determinada forma de ver y de nombrar la realidad. Otorga las reglas de formación que traban las palabras y las cosas y la lógica del linaje es precisamente la herramienta que permite la tarea interpretativa. No solo define qué se ve y qué se dice, sino cómo se articula con las prácticas sociales.

Debemos abordar la configuración mítica como modo de resaltar su lógica dominante, donde, como Detienne demostró (1986: 145-148)4, la noción de ambigüedad tensiona la díada alétheia-léthe, sin que el par implique un juego contradictorio que se auto excluya. Lo develado y lo velado conviven en el interior de un pensamiento no cercenado aún por la tiranía de una

\footnotetext{
${ }^{2}$ La presente introducción forma parte de mi tesis doctoral publicada bajo el título Hesiodo. Discurso y Linaje. Una aproximación arqueológica (2016). Se han efectuado revisiones del original.

${ }^{3}$ Para un análisis exhaustivo de la entidad de las Musas, véase Brandao (2005).

${ }^{4}$ La totalidad de la obra da cuenta de cómo se opera la declinación de esta provincia de lo mágico religiosa para posibilitar la apertura de un tópos que albergue la experiencia del lógos como lógica triunfante, como el nuevo modo de mirar y nombrar el mundo.
}

Heródoto, Unifesp, Guarulhos, v. 4, n. 1, 2019.1 p. 213-229

DOI: 10.34024/herodoto.2019.v4.10114 
lógica alethés-pseudés, en un tópos irreconciliable desde el extremo cuidado de la no contradicción, como peligro capital.

El campo mítico, articulado en la provincia de lo mágico religioso, reconoce distintas territorialidades donde opera vigorosamente un pensamiento subtendido por esta lógica: el campo poético, el mántico y el de la soberanía. Tangencialmente y como modo de situar a Hesíodo en el imaginario de su época, nos proponemos abordar el texto hesiódico desde un horizonte vinculado a la noción de arkhé. Se trata de pensar la solidaridad entre pensamiento y poder, entendiendo que el pensamiento opera como un instrumento de legitimación de conductas, instituciones y valores. El mito es una usina productora de sentido y en ese marco constituye una estructura de poder, impone un lógos dominante, una mirada-experiencia sobre lo real, que solo una nueva experiencia de saberpoder habrá de fracturar, desplegando un nuevo lógos 5 .

Sin duda, la dimensión del poder radica precisamente en esa capacidad poiética que articula efectos sobre la realidad. El mito posee entonces un efecto político en tanto transformador de lo real mismo. Es un discurso que delinea el campo de Verdad.

Lo que mantiene en escena, remarcando la metáfora teatral, una explícita configuración de pensamiento es el vigor de las fuerzas que determinaron su emergencia y que la sostienen; a saber, el mito, como estructura de pensamiento y Hesíodo constituyen, a decir de Detienne (1986: 28), el último testigo de ese tipo de palabra. El desplazamiento se da entonces por el propio debilitamiento de esas fuerzas que se agotan, clausurando el modelo ficcionado ${ }^{6}$.

A continuación, nos ubicaremos en lo que constituye el otro pilar sobre el que se asienta nuestra perspectiva de pensar a Hesíodo como una novedad. Nos referimos a la lógica del linaje presente en sus poemas. Este ha sido sin

\footnotetext{
${ }^{5}$ Seguimos en este intento de lectura las indicaciones de Michel Foucault (1979) sobre el maridaje entre saber y poder como modo de trabar la relación que guardan las palabras y las cosas en un determinado momento histórico. El saber no es sino una estructura de poder que legitima la puesta en funcionamiento de ese saber producido históricamente. ${ }^{6}$ Foucault (1979). En la conferencia "Nietzsche, la historia, la genealogía" el autor aborda la tensión Ursprung-Erfindung, origen-emergencia, recorriendo la letra nietzscheana. Se plantea la dimensión de la emergencia del acontecimiento a partir de las fuerzas que lo posibilitan por sobre la imagen estática del origen, a-histórico y no contaminado con los avatares de la historia. Foucault está buceando en la genealogía nietzscheana un nuevo modo de pensar el acontecimiento en el marco de las condiciones posibilitantes, que son siempre de carácter histórico-deviniente y no substancial.
}

Heródoto, Unifesp, Guarulhos, v. 4, n. 1, 2019.1 p. 213-229

DOI: 10.34024/herodoto.2019.v4.10114 
duda el elemento de cohesión de nuestro trabajo porque ha constituido la novedad en Hesíodo. Ya hemos definido al linaje como el operador discursivo que hilvana esa totalidad que avanza hacia formas más justas y ordenadas, tanto en el plano cósmico-divino como en el plano social; forma más ordenada en la medida en que el linaje positivo triunfa estructuralmente sobre el negativo.

Quedan delineados en los dos poemas dos territorios conceptuales que permiten clasificar esa totalidad que incorpora tanto al mundo natural como al humano en un sistema de significación compacto. Esto no implica que no aparezcan ambigüedades y mezclas, bifurcaciones y atajos no obstante, toman un perfil claro que nos permite su utilización como operador discursivo y de sentido.

Este diagrama de fuerzas que los linajes representan, constituye la llave que posibilita las ambiciones de Hesíodo,

Ambiciones por así decirlo unitarias: esas grandes y complexivas descripciones que, además, al menos en el caso de los dos primeros poemas, representan una visión idealizada: el progreso del mundo consiste en la implantación del orden de Zeus, que garantiza la justicia" (Rodríguez Adrados, 2001: 199).

En efecto, para que ese orden se dé en los términos de la sucesión cronológica que Teogonía presenta o de la implementación socio-histórica que los Érga proponen, es necesaria la lógica del linaje.

De este modo, el dispositivo del linaje se inscribe en ambos poemas como articulador de su unidad. La unidad radica en la progresiva organicidad de los sistemas, el cósmico, el divino y el humano y ese orden que se van construyendo no sin conflictividad ni tensiones, exige la presencia de ciertos operadores que delimiten los espacios sobre los que se asienta toda organización, lo diurno y lo nocturno, lo positivo y lo negativo, lo aceptable y lo rechazable, lo legal y lo ilegal, lo justo y lo injusto; en última instancia, la tensión de opuestos que da cuenta del germen mismo de lo real en su conjunto. Potencias y divinidades que se inscriben en uno u otro linaje, reyes, hombres, mujeres, instituciones, comportamientos, estilos de vida, ciudades, que se pueden leer desde una perspectiva $u$ otra. Complejidad que se juega en la dimensión agonística de los contrarios en pugna, lo cual representa un claro antecedente de formulaciones posteriores que hacen del pólemos el hilo que hilvana la constitución de lo real.

Heródoto, Unifesp, Guarulhos, v. 4, n. 1, 2019.1 p. 213-229

DOI: 10.34024/herodoto.2019.v4.10114 


\section{Las Khárites}

"Las Chárites, divinidades de la palabra, del mito cantado" (Bermejo Barrera, 1996: 63)

A la luz del marco precedente, nos detendremos en las Khárites a fin de ubicarlas en esa espesura mítica y en el linaje diurno a partir de sus marcas identitarias. Apenas unos datos que luego serán problematizados. Las Khárites son hijas de Zeus y Eurínome. En principio son divinidades de la vegetación que más tarde se transforman en divinidades de la belleza.

Hermanas de las Moûsai, su morada se halla en el Olimpo, junto a la de las nueve deliciosas hijas de la diosa Mnemosýne, lo cual marca su parentesco luminoso; cerca también se encuentra la morada de Deseo, el compañero frecuente de Afrodita. La proximidad se inscribe en una cercanía identitaria, antes que geográfica. La referencia femenina se juega en una constelación luminosa: las Moûsai, las Khárites y la propia Afrodita. Completa su pertenencia al linaje positivo y diurno la influencia que se les atribuye sobre las tareas del espíritu y las obras de arte. Constituyen la personificación de valores positivos como el júbilo, personificado por Aglaya, el placer, por Eufrósina y la felicidad, por Talía. Los atenienses solo conocen dos Khárites, ambas asociadas a la vegetación: Auxo, la que hace crecer las plantas, y Hegemoné, la que guía las plantas fuera del suelo. En realidad se las veneraba con la intención de que las cosechas fuesen abundantes.

Orcómeno, ciudad de Beocia, fundada por el rey Minias, era el lugar de culto más famoso y su templo se hallaba muy cerca del destinado a Dioniso, próximos a un manantial consagrado a la diosa Afrodita. Su culto era la proliferación de ritos muy antiguos propios de Orcómeno. El símbolo con el que se las asocia son tres grandes piedras caídas del cielo en tiempos del rey Etéocles.

Las Caritesias eran las fiestas dedicadas a las divinidades y las conocemos por inscripciones. Incluían aspectos musicales y danzas que tenían lugar durante la noche; comprendían concursos de tragedia y comedia, donde los tocadores de flauta o de cítara rivalizaban entre ellos. La asociación pues a las artes es también nítida. Pero más allá de estas noticias generales, nuestra intención es ubicarlas en el contexto hesiódico y las proyecciones que tendrán en otros autores como Píndaro por ejemplo.

Vayamos al texto para ver su presentación y su linaje de matriz diurna a partir de su gloriosa madre.

Heródoto, Unifesp, Guarulhos, v. 4, n. 1, 2019.1 p. 213-229

DOI: 10.34024/herodoto.2019.v4.10114 


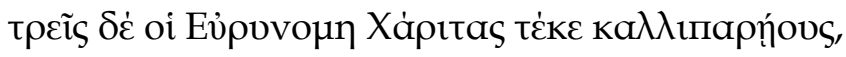

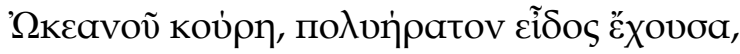

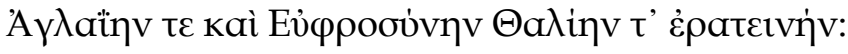

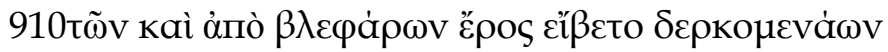

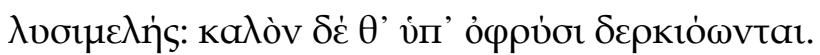

Tres Cárites le dio a luz Eurínome de hermosas mejillas,

hija de Océano de muy delicioso aspecto:

Aglya, Eufrósine y Talía agradable;

de sus ojos penetrantes se derrama el amor

que afloja miembros; bellamente bajo las cejas miran penetrante. (Teogonía, 907911).

Tal como vemos, las Khárites son el fruto del amor entre Zeus y Eurínome. Una marca alude al encanto de las tres niñas, enfatizada por el adjetivo

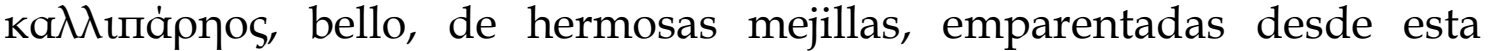
dimensión estética con las Musas quienes gozan del mismo encanto a partir de su juventud y belleza.

Su madre también está referida con un adjetivo de valencia positiva,

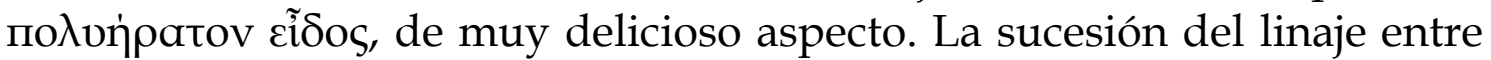
madre e hijas es así semejante a la línea que vincula a las Musas hesiódicas con su gloriosa Madre, Mnemosyne y la pertenencia a un universo femenino de matriz diurna.

Las Khárites están directamente vinculadas a eros como fuerza de cohesión; son ellas las que derraman amor. El campo lexical del verbo cí $\beta \omega$, derramar, verter, habla de su capacidad generosa para brindar amor, हैpos.

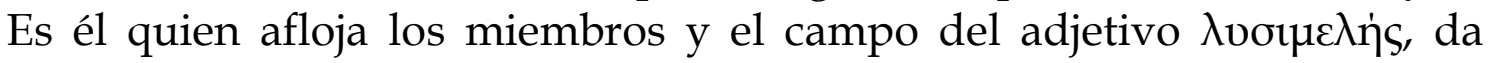
cuenta exactamente de esa condición.

Finalmente, son ellas las que miran con ojos penetrantes, remarcando su belleza. Ahora bien, la dimensión espacial de las Khárites merece algunas consideraciones que impactan directamente en nuestro proyecto de lectura. Es la contigüidad con las Musas lo que genera una condición muy particular que empieza siendo espacial y luego tiene otras derivaciones.

Heródoto, Unifesp, Guarulhos, v. 4, n. 1, 2019.1 p. 213-229

DOI: 10.34024/herodoto.2019.v4.10114 
Tal como sostiene Calame:

Las musas hesiódicas, encarnación de la poesía arcaica, producen - ¿es preciso recordarlo? - en las cercanía de Hímero y de las Chárites una melodía cantada y un ritmo de danza cuyo eco suscita el éros, cualidad personificada en el nombre mismo de la Musa Erato, que despierta el deseo (Calame, 2002: 53).

Es este grupo de potencias vinculadas a la belleza y al amor al que queremos dirigir nuestro análisis. Comencemos por el signo de una cercanía y de una familiaridad que las ubica en una misma serie luminosa y diurna. En efecto, junto a las bienhabladas hijas de Zeus, Hímero y las Khárites tienen sus casas, oỉi' '̌́Xovơv, dando cuenta de un mismo tópos que alberga elementos de valencia positiva. Es esta asociación, experta en temas de amor, la que "Teognis pone en boca de las Musas y las Chárites (Gracias) para celebrar las bodas de Cadmo y de Armonía, nacida de la unión de Ares y de Afrodita" (Calame, 2002: 126).

Si retornamos al poema hesiódico, la vecindad del grupo no es solo espacial. La contigüidad geográfica se inscribe en una alianza funcional. Bermejo Barrera extiende la asociación a una misma función, habitualmente reservada a las Musas. El autor indica al colectivo como artífices del canto, ya que en los tres versos que considera interpolados, "se dice que cantan en las fiestas las leyes y alaban los sabios principios comunes a todos los inmortales" (1996: 60). Jugando con esta interpretación se amplía la función celebratoria y ese colectivo asociado al amor y al encanto constituiría una estructura de saber-poder en el marco de la economía olímpica.

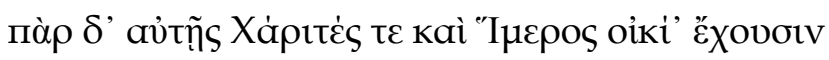

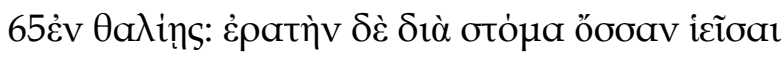

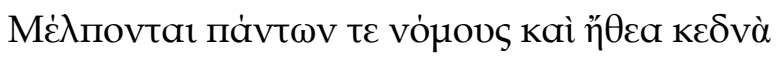

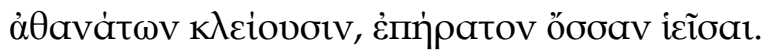

y junto a ellas las Cárites y también Hímero tienen sus casas;

en los banquetes, emitiendo su amable voz por la boca,

cantan las leyes de todos, y las costumbres respetables

de los inmortales celebran, emitiendo su muy amable voz. (Teogonía, 64-67).

Heródoto, Unifesp, Guarulhos, v. 4, n. 1, 2019.1 p. 213-229

DOI: 10.34024/herodoto.2019.v4.10114 
Lo primero que aparece es una convivencia en los banquetes, غ̇v $\theta a \lambda i n$ s $_{\text {, }}$ inscribiendo la función celebratoria en el marco festivo adecuado a la palabra de alabanza. El uso del participio, icĩoal, da cuenta de la función a partir del campo lexical del verbo, derramar, verter, emitir, dejar oír. Esta acción es complementaria del verso siguiente, inscribiendo el campo lexical del verbo $\mu \varepsilon \dot{\lambda} \Pi \omega \omega$, celebrar con la danza y el canto, cantar y bailar, en una función festiva que las ubica en el escenario de la belleza y el encanto como marcas identitrias. Las bellas damas emiten su voz inmortal, öoбav, dando cuenta de un tipo de saber que las ubica en un tópos de poder.

Tal como sostiene Bermejo Barrera, "en estos versos las Gracias son sinónimos de las Musas, y uno de los caracteres básicos de ese grupo de mujeres era el cantar el orden olímpico y sus principios" (Barrera, 1996: 61). Esta es la clave de la asociación que propone el autor y el valor de la función celebratoria tal como la venimos relevando. Se trata de una fuerza femenina al servicio de la conservación del orden cósmico. Si más tarde el poeta va a constituirse como "funcionario de la soberanía" al narrar la creación en el mismo momento en que el rey mima el combate fundacional que instaura la soberanía cósmica (Detienne, 1986: 21-38), a este nivel del relato mítico, el colectivo femenino cumple una función análoga, sirviendo con su divina voz, őoøa, a Zeus, el garante del orden cósmico. Se trata de una función clave en el ordenamiento cósmico que da cuenta, además, de una línea sucesoria entre las Khárites y su madre Eurínome, el Buen Orden.

Vuelve a aparecer una línea directa en la sucesión de un linaje diurno que, de madre a hijas, da cuenta de un saber que colabora directamente con el Soberano en su gesta organizadora de lo real. Coincidimos con Bermejo cuando afirma,

El canto de este coro está pues en Hesíodo asociado a los principios legales y al orden cósmico, transmitidos a Zeus a través de su matrimonio anterior. La asociación de las Chárites con el orden del mundo, con los reyes y la Función, deriva en parte del propio carácter de su madre Eurínome (Barrera, 1996: 61).

Las coincidencias llegan pues a la línea ascendente del linaje materno. Las Musas heredan de su madre la maravillosa voz asociada a la Memoria sacralizada, aquella que sabe lo que fue, lo que es y lo que será. Mnemosyne es una omnisciencia de carácter adivinatorio que habilita a sus hijas a cantar la gloria del Padre. Las Khárites reciben de su madre una función análoga; una dimensión celebratoria que pone al orden y a la legalidad en el centro de la escena. Doblete estructural donde Mnemosyne es a Eurínome lo que las Musas son a las Khárites. De madres a hijas se instituye una función que hace de la celebración y la alabanza una fuerza cosmificante.

Heródoto, Unifesp, Guarulhos, v. 4, n. 1, 2019.1 p. 213-229

DOI: 10.34024/herodoto.2019.v4.10114 
Merece alguna consideración la elección de Zeus en relación con sus mujeres. Mnemosyne le ha brindado nueve deliciosas hijas que lo celebran y mantienen su nombre asociado a la soberanía. Eurínome le ha brindado otras tantas hijas que asociadas a las primeras, constituyen un colectivo también al servicio de la soberanía del Padre. Tal como sostiene Bermejo, "En este matrimonio, como en los anteriores, por consiguiente, Zeus se asocia a una mujer preolímpica que posee un poder indudablemente relacionado con la soberanía" (Barrera, 1996: 61). De este modo, ambas esposas brindarán a través de sus deliciosas hijas, el poder del canto, afín al mantenimiento del orden soberano que, como sabemos, termina de corroborar el poeta. Por eso, son ellas, las Musas, las que lo invisten con un cetro de florido laurel para perpetuar su propia función divina.

\section{Más allá de Hesíodo}

A continuación nos proponemos tomar otro testimonio sobre las Khárites para confirmar algunos aspectos identitarios y funcionales que venimos rastreando. En primer lugar trabajaremos la Olímpica XIV de Píndaro, fechada probablemente en el 488, donde el poeta se dirige elogiosamente a las diosas. La tradición indica que el poeta mismo dirige en el 448 la celebración del triunfo de Asópico de Orcómeno. Es en Orcómeno donde las Khárites tienen un santuario y es a ellas a quienes Asópico debe su triunfo en el estadio olímpico. Comencemos por la primera estrofa

¡Vosotras, que las ondas del Cefiso obtuvisteis

del destino y que habitáis el paraje de hermosos corceles,

Oh Gracias, dignas de ser celebradas en cantos, reinas

de la espléndida Orcómeno, protectora de los Minias antiguos,

Escuchadme, os lo ruego! Pues por vosotras se otorga alegría

y toda dulzura a los mortales,

cuando alguien es sabio o de hermosa figura o famoso.

Porque, sin las Gracias augustas, ni siquiera los dioses

ordenan sus festines y danzas; sino que en el cielo son ellas

servidoras de todas las cosas, ocupando sus tronos

al lado de Apolo Pitio, el del arco de plata,

Heródoto, Unifesp, Guarulhos, v. 4, n. 1, 2019.1 p. 213-229

DOI: 10.34024/herodoto.2019.v4.10114 
y adoran la majestad eterna de su Olímpico Padre (1-12).7

La semejanza con la invocación de las Musas es notoria. El poeta se dirige a las Khárites, solicitándoles su atención, tal como lo hace Hesíodo de quien se siente un eterno servidor.

Las primeras marcas son de carácter espacial ya que las diosas reinan sobre las olas del Cefiso, pequeño río costero que atravesaba Beocia y que, según Pausanias en Descripción de Grecia (9.38.7), recogiendo una tradición tebana, fue desviado por Heracles hacia la llanura de Orcómeno. De allí su parentesco con "la espléndida Orcómeno", donde se halla el santuario que las celebra con cantos, tal como son celebradas las Musas por el canto eterno del poeta. Protectoras de los minias, pueblo beocio, primero en recibir un nombre entre los pelasgos, situado en Orcómeno; el dato refuerza su inscripción en la región, simbólicamente la misma en la que se inscribe Hesíodo.

El parentesco con las Musas esta atestiguado en la función festiva: "Pues por vosotras se otorga alegría y toda dulzura a los mortales". Khárites y Musas están inscritas en el mismo linaje diurno a partir de esta prodigalidad de ternura, dulzura y alegría, propia, por otro parte, de su condición de Hijas de un gloriosísimo Padre. En el caso de las Musas esta función de prodigar alegría está directamente emparentada con una función terapéutica de calmar las preocupaciones de los mortales y de los Inmortales. En este caso la alegría está al servicio de deleitar a los mortales sabios, de hermosa figura o famosos, vale decir aquellos que se hallan inscritos en un mismo linaje diurno. Tal como sostiene Bermejo Barrera son "consideradas como dadoras de todo lo agradable, especialmente del renombre para los hombres" (1996: 64). Como sus afamadas hermanas, las Khárites representan el principio de inteligibilidad que separa los campos de lo encantador y agradable de aquello que no lo es. En última instancia son operadoras de sentido y territorializan todo lo bueno y amoroso en un campo que se erige socialmente como aquello que se apetece en oposición a las figuras de genealogía monstruosa.

Hay una mención interesante en torno a cierta dependencia de los dioses en relación con ellas, ya que "sin las Gracias augustas, ni siquiera los dioses ordenan sus festines y danzas". La dimensión funcional queda así atestiguada en Píndaro. Son las verdaderas artesanas de la alegría de los Inmortales al organizar sus encuentros, amenizados por sus danzas. Estas "servidoras de todas las cosas" son figuras femeninas de fuerza innegable.

\footnotetext{
${ }^{7}$ Píndaro, Olímpica, XIV

Heródoto, Unifesp, Guarulhos, v. 4, n. 1, 2019.1 p. 213-229

DOI: 10.34024/herodoto.2019.v4.10114
} 
Se trata de un colectivo potente que aúna el poder de servir a los Inmortales con el saber hacerlo. Sin duda, el mayor servicio es la alabanza de la majestad de Zeus, "la majestad eterna de su Olímpico Padre", y este tópico resulta un nuevo punto de encuentro con sus diurnas hermanas.

Son las encantadoras hijas que el Padre necesita para mantener su soberanía cantada, su poder eternamente narrado por la maravillosa voz del canto femenino. Nacimientos funcionales a la gloria del Soberano donde Mnemosyne y Eurínome cumplen un papel fundamental, convirtiéndose en las gloriosísimas damas capaces de reproducir lo que Zeus necesita para garantizar y perpetuar su poder y con ello asegurar el orden cósmico y social. No hay gloria sin canto. Es la misma lógica que se refleja en la condición guerrera. El mundo divino inaugura un modelo de funcionamiento donde el poder del canto genera la gloria misma. La palabra cobra así una dimensión ontológica ya que otorga el ser del hombre cantado.

Dos potencias parecen ser temibles en este marco de pensamiento: la Alabanza y la Desaprobación. En realidad, se trata de dos bisagras dominantes de la lógica guerrera porque determinan procesos de territorialización y desterritorialización, de visibilidad e invisibilidad, de aparición y desaparición. Incluso, las dos nociones dominantes se juegan, a nuestro entender, en una metáfora lumínica que determina zonas de luz y oscuridad, que recaen directamente sobre la figura del guerrero, marcando su reconocimiento y aprobación social o bien su desaprobación, articulada en muerte. El hombre homérico adquiere conciencia de su valor por el reconocimiento de la sociedad a la que pertenece. Es un producto de su clase y mide su propia excelencia por la opinión de sus semejantes (Jaeger, 1995: 25). Se trata de una lógica que tensiona dos polos antitéticos: alétheia-léthe. En efecto, la aprobación se juega en el horizonte de la verdad, en tanto des-oculto, de-velado. El honor quita el velo del oprobio, devela y descubre el ser del guerrero. Por el contrario, el des-honor cubre y vela el buen nombre y la fama. El hombre queda así oscurecido, cubierto detrás del velo del anonimato.

Un mismo dispositivo donde la palabra es el camino de acceso a la verdad. Las Khárites mantienen con su canto el ser mismo de la Soberanía, como lo hacen las Musas y los poetas en tanto funcionarios de esa soberanía.

La segunda estrofa nos acerca nuevas marcas identitarias que refuerzan la territorialización de las tres hermanas en el linaje luminoso que venimos rastreando:

Heródoto, Unifesp, Guarulhos, v. 4, n. 1, 2019.1 p. 213-229

DOI: 10.34024/herodoto.2019.v4.10114 


\begin{abstract}
¡Oh Áglae, señora,
Y tú Eufrósina, de canciones amiga, hijas del más poderoso

de los dioses, oídme benévolas ahora, y también tú, Talía,

que amas los cantos, mientras este cortejo contemplas

que ligero camina (danza) con motivo de la buena fortuna! ${ }^{8}$
\end{abstract}

Las tres están caracterizadas con adjetivos amables que acentúan las marcas luminosas del colectivo, al tiempo que se corrobora la afición por el canto y la danza, tal como Eufrósina, de canciones amiga, o la propia Talía, que ama los cantos y camina ligero en el sentido que danza, sellando una vez más una dimensión funcional que las asocia a las Musas, amantes del canto y la danza, que bellos coros forman junto a su Padre, engalanando el Olimpo.

\title{
La asociación con la belleza
}

Si bien hasta el momento hemos recorrido un camino que podemos ubicar en el tópos de la belleza, hay una función específica en torno a la belleza del cuerpo que también las tiene como protagonistas.

Hesíodo y Homero dan cuenta de esta dimensión funcional que las asocia al encanto y al amor. Tal como señala Bermejo Barrera "En los poemas homéricos sus actividades son fundamentalmente dos: el tejido de las telas y el cuidado corporal, y la danza y el canto en un choros. Y por estas dos actividades se vinculan estrechamente a Afrodita" (1996: 65). El canto VIII de Odisea alude a esta nueva dimensión que ponemos en circulación. Cuando la risueña Afrodita partió para Pafo de Chipre donde se encuentra su altar coronado de ofrendas, "al llegar la lavaron las Gracias, la ungieron de aceite inmortal, del que brilla en la piel de los dioses eternos, y vistiéronla ropas preciosas, hechizo a los ojos" (Od. VIII, 362-366).

Los versos evocan sin duda, el dispositivo ritual de engalanar a Pandora como la primera novia de Occidente (Leduc, 1992) donde también participan las Gracias como muy pronto veremos. Homero las presenta en una función que refuerza la femineidad del colectivo. Son ellas las que, asociadas al encanto y a la belleza, engalanan a Afrodita. Es una nueva arista del sema dominante del encanto y de la seducción. Así como produce

\footnotetext{
${ }^{8}$ Píndaro, Olímpica XIV

Heródoto, Unifesp, Guarulhos, v. 4, n. 1, 2019.1 p. 213-229

DOI: 10.34024/herodoto.2019.v4.10114
} 
deleite el canto y la danza, del mismo modo la belleza femenina constituye un "hechizo a los ojos". El baño, el aceite inmortal y las ropas preciosas forman la trama de un ritual femenino donde se enseñorea la seducción y el amor.

Así, si pensamos en la línea de continuidad en torno al tópico del encanto, Trabajos y Días se refiere a ellas a la hora de embellecer a Pandora en el marco del ritual que engalana a la primera mujer. Son ellas quienes coronan a Pandora con flores, según refiere Hesíodo en estos términos:

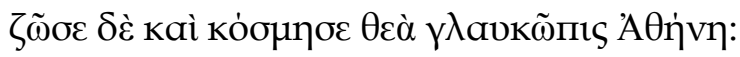

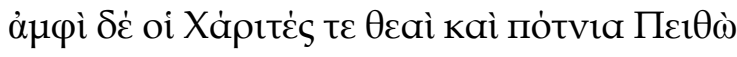

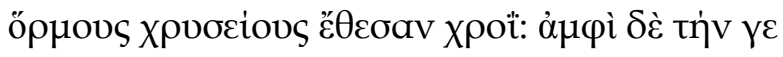

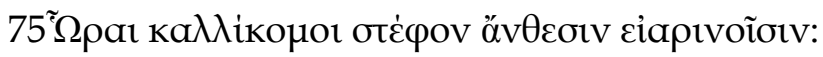

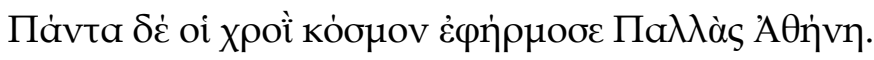

"le dio vida y la adornó la diosa de ojos glaucos Atenea;

Las Cárites divinas y la augusta Peito

en torno de su cuerpo colocaron collares dorados; y a su alrededor

las Horas de hermosos cabellos la coronaron con flores primaverales;

todo el ornato a su cuerpo aplicó Palas Atenea" (Trabajos y días, 75).

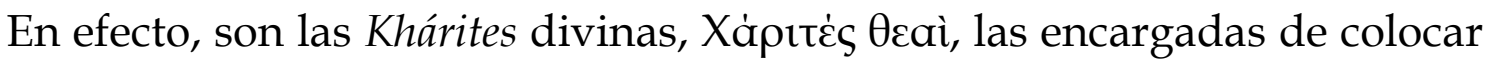
las bellas joyas que engalanan a la novia, ritual presidido por Atenea. La presencia de un nuevo colectivo, las Horas de hermosos cabellos, ка $\lambda \lambda$ iконо, refrendan la tarea cosmética de coronarla con bellas flores de primavera.

Pensemos en ellas como un breve atajo que contribuye a leer la valencia positiva de ciertos colectivos afines en el marco del dispositivo mítico como lógos explicativo que obedece a una intrincada arquitectura de sentido. Alcanza con observar la imagen para asociar iconográficamente una similitud con los colectivos femeninos que venimos rastreando.

Antes de su aparición en la Teogonía hesiódica, las Horas brotan ya en Ilíada como guardianas de las puertas del Olimpo, una puerta que se abre y se cierra para juntar o dispersar las nubes. Son divinidades sonrientes que

Heródoto, Unifesp, Guarulhos, v. 4, n. 1, 2019.1 p. 213-229

DOI: 10.34024/herodoto.2019.v4.10114 
presiden todo aquello que llega a su hora, como un fruto maduro que cae del árbol en el momento preciso. Allí están, en las bodas de Tetis y Peleo; tutelan también el crecimiento de la vegetación, porque simbolizan fenómenos naturales y suelen, como las Gracias, de quienes se hallan muy próximas por características afines, aparecer danzando. Rigen el nacimiento y el casamiento, pero no la muerte porque están siempre presentes en momentos dichosos.

Las marcas identitarias continúan bordando una experiencia festiva a partir no solo del canto y de la danza, sino de un cierto modelo de instalación en la economía general del pensamiento mítico. Musas, Khárites y Horas responden a esa necesidad del Olimpo de contar con una cuota de juventud y belleza que llene de encanto y felicidad las moradas Olímpicas.

\section{Conclusiones}

El proyecto de presente trabajo consistió en primer lugar en revisar la función del discurso mítico en la producción de Hesíodo para pensarlo como un operador que instituye un universo de sentido como efecto de verdad y que se halla en una zona ambigua de sendas embrolladas entre la estructura del mito y la filosofía.

En este marco intentamos destacar la figura de las Khárites quienes, a partir de ciertas marcas identitarias y funcionales, resultaron estar asociadas a las Musas; esta asociación nos permitió rastrear formas del poder femenino, leído a partir de un determinado tipo de saber que se despliega en su accionar. Así, nos detuvimos en las Khárites a fin de ubicarlas en esa espesura mítica dentro del discurso hesiódico y más allá de él, territorializándolas en el escenario de esa lógica del linaje, al corresponderles uno diurno a partir de esas marcas identitarias. Potencias vinculadas a la belleza, al encanto, la seducción y al amor constituyeron el blanco al que dirigimos nuestro análisis.

Comenzamos por la cercanía espacial. En efecto, tal como analizamos, las Khárites tienen sus casas junto a las delicadas hijas de Zeus, Hímero y el Deseo, dibujando un mismo tópos que alberga elementos de valencia positiva.

Nos detuvimos en el análisis de Bermejo Barrera para pensar la clave de la asociación que propone el autor entre ambos colectivos, postura con la que coincidimos, y ver el predominio de la función celebratoria como aquella

Heródoto, Unifesp, Guarulhos, v. 4, n. 1, 2019.1 p. 213-229

DOI: 10.34024/herodoto.2019.v4.10114 
dimensión que los emparienta en una instalación común dentro de la economía del mito. Su vinculación con el poder y el saber es la condición de una fuerza de matriz femenina al servicio de la conservación y cuidado del orden cósmico. Si más tarde en el nivel de la poesía como función socio religiosa, el poeta inspirado se erigirá como un "funcionario de la soberanía", a este nivel del relato mítico, el colectivo femenino cumple una función rectora y análoga, sirviendo con su divina voz, őoøa, a Zeus, el garante del orden cósmico, aquel que representa el principio de inteligibilidad de una legalidad que encuentra en el divino canto su materialidad.

A continuación, nos propusimos transitar otro testimonio sobre las Khárites para corroborar algunos rasgos identitarios y funcionales que el relato hesiódico había desplegado. Para tal proyecto, trabajamos la Olímpica XIV de Píndaro, pieza donde el poeta se dirige elogiosa y amorosamente a las diosas. El parentesco estructural con las Musas queda claramente atestiguado en la función celebratoria que las asocia y familiariza en una idéntica huella identitaria.

Khárites y Musas están inscritas en el mismo linaje diurno a partir de su claridad, de esa exuberancia de ternura, dulzura y alegría, que se derrama pródigamente y que es propia de su condición genealógica al ser hijas de un gloriosísimo Padre y de unas madres relevantes.

Si bien el trabajo se movió dominantemente en el tópos de la belleza, recorrimos también una función específica en torno a la belleza del cuerpo que las tiene como protagonistas. Tanto Hesíodo como Homero dan cuenta de esta dimensión funcional que las asocia al encanto y al amor. Musas, Khárites e incluso las Horas responden a esa necesidad política del dispositivo Olímpico de contar con una dulce cuota de juventud, belleza, encanto y seducción que colme de felicidad las moradas de los Inmortales.

\section{Referencias bibliográficas}

BARRERA BERMEJO, Juan Carlos, GONZÁLEZ GARCÍA, Francisco Javier, REBOREDA MORILLO, Susana. Los orígenes de la mitología griega. Madrid: Akal, 1996.

BRANDAO, Jacyntho Lins. Antiga Musa (Arqueología da fição). Belo Horizonte: FALE, 2005.

CALAME, C. Eros en la antigua Grecia, Madrid, Akal, 2002.

Heródoto, Unifesp, Guarulhos, v. 4, n. 1, 2019.1 p. 213-229

DOI: 10.34024/herodoto.2019.v4.10114 
COLOMBANI, María Cecilia. Hesíodo. Discurso y Linaje. Una aproximación arqueológica. Mar del Plata: EUDEM, 2016.

DETIENNE, Marcel. Los maestros de verdad en la Grecia Arcaica. Madrid: Taurus, 1986.

FOUCAULT, Michel. "Entrevista sobre la prisión: el libro y su método". En: Idem. Microfisica del poder., Madrid: Ediciones La Piqueta, 1979.

HESÍODO. Obras y fragmentos. Gredos, Madrid. 2000

HESIOD. Theogony. Works and Days. Testimonia. Most, G. W. Loeb Classical Library. London: Harvard University Press, 2006.

HOMERO. Odisea. Madrid: Gredos, 2000.

JAEGER, Werner. Paideia. México: Fondo de Cultura Económica, 1995.

LEDUC, Claudine. “¿Cómo darla en matrimonio? La novia en Grecia, siglos IX-IV a. C.". En: Duby, George, Perrot, Michelle. Historia de las Mujeres, 1. La Antigüedad, Madrid: Taurus, 1992.

LIDDEL, H. G., SCOTT, R. A Greek-English Lexicon. Oxford: Clarendon Press, 1996.

LIÑARES, Lucía. Teogonía, Trabajos y Días. Edición bilingüe. Buenos Aires: Losada, 2005.

RODRÍGUEZ ADRADOS, F. (2001) "La composición de los poemas hesiódicos", EMÉRITA, Revista de Lingüística y Filología Clásica. LXIX, 2, 2001, pp. 197-223.

VIANELLO DE CÓRDOVA, Paola. Teogonía. México: Universidad Nacional Autónoma de México, 1978. 